\title{
CONSTRUCTAL THEORY APPLIED TO THE GEOMETRIC OPTIMIZATION OF ELLIPTICAL CAVITIES INTO A SOLID CONDUCTING WALL
}

\begin{abstract}
L. A. O. Rocha ${ }^{a}$, ABSTRACT
C. Biserni ${ }^{\mathrm{b}}$

and E. Lorenzini ${ }^{\mathrm{b}}$

${ }^{\text {a }}$ FURG - Universidade Federal do Rio Grande

Escola de Engenharia, Av. Itália, km 8,

96201-900 Campus Carreiros, Cx. P. 404,

Rio Grande, RS, Brasil

laorocha@gmail.com

This work reports, according to Bejan's Constructal theory, the geometric optimization of an elliptical cavity that intrudes into a solid conducting wall. The objective is to minimize the global thermal resistance between the solid and the cavity. There is uniform heat generation on the solid wall. The cavity is optimized for two sets of thermal conditions: isothermal cavity and cavity bathed by a steady stream of fluid. The solid conducting wall is isolated on the external perimeter. The total volume and the elliptical cavity volume are fixed while the geometry of the cavity is free to vary. The results show that the optimized geometrical shapes are relatively robust, i.e., insensitive to changes in some of the design parameters: the cavity shape is optimal when penetrates the conducting wall almost completely.
\end{abstract}

${ }^{\mathrm{b}}$ Alma Mater Studiorum, Dipartimento di

Ingegneria Energetica, Nucleare e del

Controllo Ambientale, Viale Risorgimento 2,

40136 Bologna, Italy
Keywords: Constructal theory, heat transfer enhancement, optimal geometry

\section{NOMENCLATURE}

a dimensionless parameter, Eqs.( 9)-(10)

A area, $\mathrm{A}=\mathrm{HL}, \mathrm{m}^{2}$

$\mathrm{h}$ heat transfer coefficient, $\mathrm{W} \mathrm{m} \mathrm{m}^{-2} \mathrm{~K}^{-1}$

$\mathrm{H}$ height, $\mathrm{m}$

$\mathrm{H}_{0} \quad$ half-axis length of the ellipses in the y

direction, $\mathrm{m}$

$\mathrm{k} \quad$ solid thermal conductivity, $\mathrm{W} \mathrm{m} \mathrm{m}^{-1} \mathrm{~K}^{-1}$

$\mathrm{L}$ length, $\mathrm{m}$

$\mathrm{L}_{0} \quad$ half-axis length of the ellipses in the $\mathrm{x}$

direction, $m$

n direction normal to the cavity

q"' heat generation rate per unit volume, $\mathrm{W} \mathrm{m}^{-3}$

$\mathrm{T}$ temperature, $\mathrm{K}$

To free-stream temperature, $\mathrm{K}$

$\mathrm{V}$ volume, $\mathrm{m}^{3}$

$\mathrm{V}_{0} \quad$ cavity volume, $\mathrm{m}^{3}$

$\mathrm{W}$ width, $\mathrm{m}$

$\mathrm{x}, \mathrm{y} \quad$ cartesian coordinates, $\mathrm{m}$

\section{Greek symbol}

$\phi \quad$ volume fraction occupied by the cavity

\section{Superscripts}

( ) dimensionless variables, Eqs. (4)-(7)

\section{Subscripts}

$\max$ maximum

min minimum

opt optimum

ref reference

\section{INTRODUCTION}

The maximization of the rate of heat transfer in a given volume has become the basic principle of designing structures for heat and fluid flow. This paper documents numerically the relation between the maximization of global performance and the morphing architecture of a flow system. Bejan's Constructal Theory (Bejan, 2000) serves as a reminder that flow systems (to be optimized) must be considered as malleable, i.e., as morphing structures that are as free to change as possible. The morphing configuration here treated is an open cavity formed by an elliptical intrusion into a solid conducting wall. The generated heat current in the external solid is removed by cooling the wall of the cavity. The global performance indicator is the overall thermal resistance between the entire system (solid and cavity) and the surroundings. An important thermal design constraint is that temperatures have not to exceed a certain threshold. This approach is consistent to the constructal method (Bejan, 1997 and Bejan, 2000), where design is the result of a 
"permanent struggle for better and better global system performance under global constraints".

It is well known that constructal theory proved to be interdisciplinary, with implications in engineering (Lorenzini and Rocha, 2006, Lorenzini conjunction with radiation has demonstrated increased effectiveness in the treatment of certain types of cancer, such as skin cancer. The objective is to control heating of the tumor so that the temperature of the normal tissue surrounding the tumor remains low enough so as not to cause damage to the tissue. Ref. (Arion et al., 2003) documents an integral approach to the evaluation and maximization of performance in the design of networks for the distribution of electric power.

In this paper we rely on the constructal method in its original engineering sense, by focusing on the optimization of architecture. Volume-to-point (or area-to-point) heat conduction problem was initially defined by Bejan in Ref. (Bejan, 1997) as follows: consider a finite volume heated uniformly, with a finite amount of high conductivity material. Determine its optimal and Moretti, 2007), nature (Bejan, 1998), management (Bejan and Badescu, 2000), etc...

In Ref. (Wang et al., 2007), for example, it has been extended to cancer treatments.

Conventional hyperthermia in distribution trough the given volume such that the highest temperature, i.e. the hot spot, is minimized.

The statement of the problem here treated is not conceptually different from the above mentioned Bejan's conduction problem: in this paper we contemplate the presence of the morphing cavity (that removes heat) instead of the insertion of the high conductivity material, i.e. the conduction path. For sake of clarity, we consider twodimensional geometries where the overall volume is a rectangular body and the cavity volume has an elliptical shape (Figure 1). The rectangular body and the elliptical cavity have variable geometric aspect ratios. Two thermal boundary conditions have been examined for the elliptical cavity: isothermal wall at $T_{\min }$ and wall cooled by a steady stream with heat transfer convection, $h$, and temperature To.

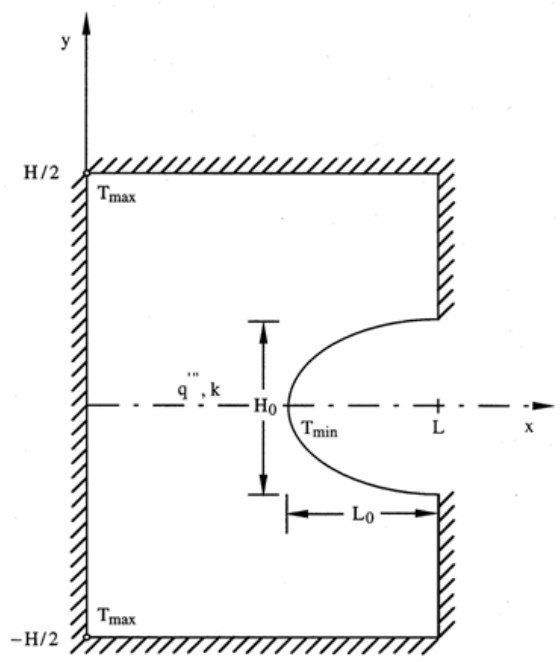

Figure 1. Isothermal cavity into a two-dimensional conducting body with uniform heat generation.

\section{NUMERICAL FORMULATION AND RESULTS}

Consider the two-dimensional conducting body shown in Fig. 1. The external dimensions ( $\mathrm{H}, \mathrm{L})$ vary. The third dimension, $\mathrm{W}$, is perpendicular to the plane of the figure. The total volume occupied by this body is fixed,

$$
\mathrm{V}=\mathrm{HLW}
$$

Alternatively, we may say that the area $\mathrm{A}=\mathrm{HL}$ is fixed. The dimensions of the cavity $\left(\mathrm{H}_{0}, \mathrm{~L}_{0}\right)$ vary. The cavity volume is fixed,

$$
\mathrm{V}_{0}=\frac{\pi \mathrm{L}_{0} \mathrm{H}_{0} \mathrm{~W}}{4}
$$

This volume constraint may be replaced by the statement that the volume fraction occupied by the cavity is fixed,

$$
\phi=\frac{\mathrm{V}_{0}}{\mathrm{~V}}=\frac{\pi}{4} \frac{\mathrm{L}_{0} \mathrm{H}_{0}}{\mathrm{LH}}
$$

The solid is isotropic with the constant thermal conductivity $\mathrm{k}$. It generates heat uniformly at the volumetric rate $\mathrm{q}^{\prime \prime}\left[\mathrm{W} / \mathrm{m}^{3}\right]$. The outer surfaces of the heat generating body are perfectly insulated. The generated heat current (q"'A) is removed by cooling the wall of the cavity. The cavity wall temperature is maintained at $\mathrm{T}_{\text {min }}$. Temperatures rise to levels higher than $\mathrm{T}_{\min }$ in the solid. The highest temperatures (the "hot spots") are registered at points on the adiabatic perimeter, for example, in the two corners indicated with $\mathrm{T}_{\max }$ in Fig. 1. 
A global constructal design constraint is the requirement that temperatures must not exceed a certain level. This makes $\mathrm{T}_{\max }$ a constraint. In the present problem statement, the design objective is represented by the maximization of the global thermal conductance $\mathrm{q}^{\prime \prime} \mathrm{A} /\left(\mathrm{T}_{\max }-\mathrm{T}_{\min }\right)$, or by the minimization of the global thermal resistance $\left(\mathrm{T}_{\max }-\right.$ $\left.\mathrm{T}_{\min }\right) /\left(\mathrm{q}^{\prime \prime \prime} \mathrm{A}\right)$. This objective is achieved through the generation of an optimal shape of the body geometry.

The numerical optimization of geometry consisted of simulating the temperature field in a large number of configurations, calculating the global thermal resistance for each configuration, and selecting the configuration with the smallest global resistance. Symmetry allowed us to perform calculations in only half of the domain, $y \geq 0$. The conduction equation for the solid region is

$$
\frac{\partial^{2} \widetilde{\mathrm{T}}}{\partial \widetilde{\mathrm{x}}^{2}}+\frac{\partial^{2} \widetilde{\mathrm{T}}}{\partial \widetilde{\mathrm{y}}^{2}}+1=0
$$

where the dimensionless variables are

$$
\begin{gathered}
\widetilde{T}=\frac{T-T_{\min }}{\mathrm{q}^{\prime \prime}{ }^{\prime \prime} \frac{\mathrm{A}}{\mathrm{k}}} \\
\left(\widetilde{\mathrm{x}}, \widetilde{\mathrm{y}} \cdot \widetilde{\mathrm{H}}, \widetilde{\mathrm{H}}_{0}, \widetilde{\mathrm{L}}_{0}\right)=\frac{\left(\mathrm{x}, \mathrm{y} \cdot \mathrm{H}, \mathrm{H}_{0}, \mathrm{~L}_{0}\right)}{\mathrm{A}^{1 / 2}}
\end{gathered}
$$

The boundary conditions are indicated in Fig. 1 . The maximal excess temperature, $\widetilde{\mathrm{T}}_{\max }$, is also the dimensionless global thermal resistance of the construct,

$$
\widetilde{\mathrm{T}}_{\max }=\frac{\mathrm{T}_{\max }-\mathrm{T}_{\text {min }}}{\mathrm{q}^{\prime \prime \prime} \frac{\mathrm{A}}{\mathrm{k}}}
$$

Equation (4) was solved using a finite elements code, based on triangular elements, developed in MATLAB environment, specifically, the pde (partialdifferential-equations) toolbox (Matlab User's Guide, 2000). The procedure to achieve mesh independence and validation of results is the same used in Refs. (Biserni et al., 2004 and Rocha et al., 2005), and it is not shown.

The numerical work consisted of determining the temperature field in a large number of configurations of the type shown in Fig.1.

Fig. 2 shows that the thermal resistance can be minimized by selecting the shape of the cavity. The thermal resistance decreases when the volume fraction $(\phi)$ occupied by the cavity increases.

The results calculated in Fig. 2 are consolidated in Fig. 3, where the minimal (optimized) global thermal resistance and optimal internal shape of the elliptical cavity are shown as a function of the volume fraction of the cavity, $\phi$.

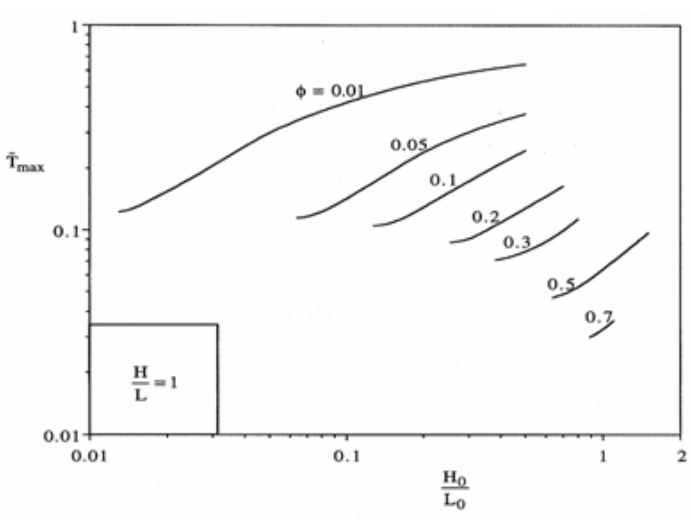

Figure 2. The minimization of the global thermal resistance when the external shape of the heat generating body is fixed.

The second level of the numerical optimization scheme consisted of repeating the preceding work (Figs. 2 and 3) for several values of the second shape parameter, H/L. The most important finding (Fig. 4) is the existence of the optimal $\mathrm{H} / \mathrm{L}$ ratio, i.e., the geometry of Fig. 1 can be optimized with respect to two degrees of freedom. The optimal ratio $(\mathrm{H} / \mathrm{L})_{\text {opt }}$ is its smallest value possible for each value of the volume fraction $\phi$, i. e., the elliptical cavity performs better when it penetrates almost completely into the wall.

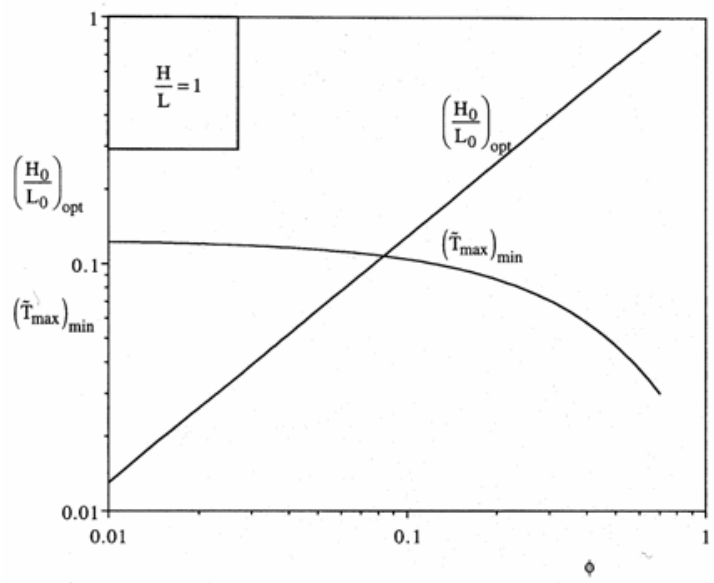

Figure 3. The optimized geometry and performance when the external shape is square.

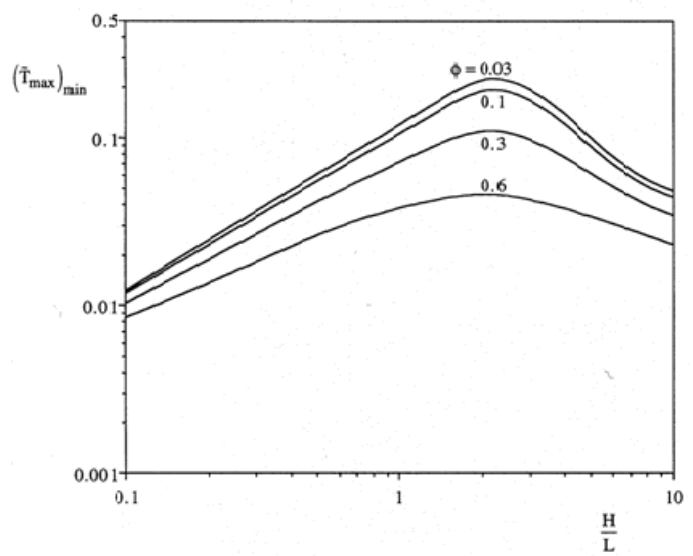


Figure 4. The effect of the external shape H/L on the global thermal resistance minimized as in Fig. 2.

Figure 5 shows the optimal internal shape of the elliptical cavity corresponding to the global thermal resistances explored in Fig. 4. It is possible to observe that there is a unique best shape of the internal cavity for all $(\mathrm{H} / \mathrm{L})$ values, except for $\mathrm{H} / \mathrm{L}=$ 2. When $\mathrm{H} / \mathrm{L}$ is equal to 2 can exist two possibilities for the optimal internal shape $\left(\mathrm{H}_{0} / \mathrm{L}_{0}\right)_{\mathrm{opt}}$, depending on the value of the volume fraction. Figure 6 shows some of the best shapes for several values of the volume fraction $\phi$ and $\mathrm{H} / \mathrm{L}=2$.

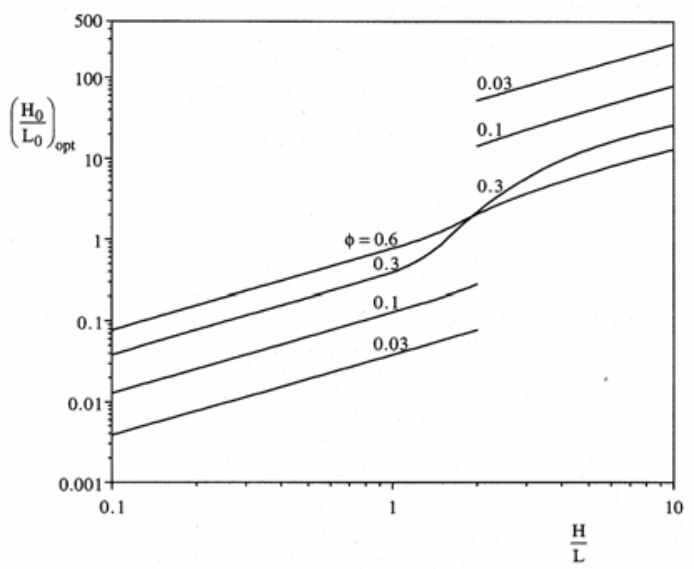

Figure 5. The effect of the external shape $\mathrm{H} / \mathrm{L}$ on the optimal ratio $\left(\mathrm{H}_{0} / \mathrm{L}_{0}\right)_{\mathrm{opt}}$ as in Fig. 2.
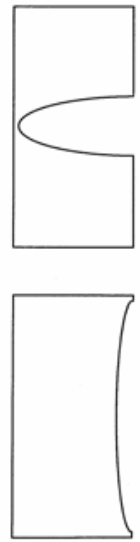

$\varphi=0.1$
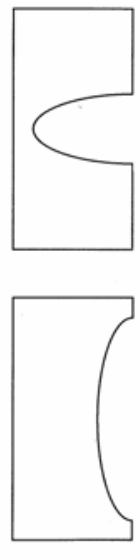

$\varphi=0.2$

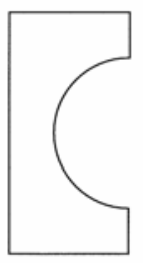

$\phi=0.3$

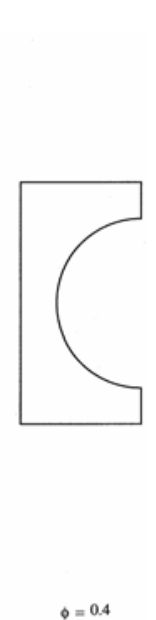

Figure 6. The best shapes calculated in Fig. 5 when $\mathrm{H} / \mathrm{L}=2$.

\section{BODY COOLED BY CONVECTION}

This section examines the elliptical cavity shown in Fig. 1 where all the geometry parameters are the same, except by the boundary condition on the elliptical cavity wall that now is cooled by a steady stream with heat transfer convection coefficient, h, and temperature $\mathrm{T} \infty$. The dimensionless temperature is defined by

$$
\widetilde{T}=\frac{T-T_{\infty}}{q^{\prime \prime \prime} \frac{A}{k}}
$$

and the boundary condition in the direction normal to the cavity wall is given by

$$
-\frac{\partial \widetilde{\mathrm{T}}}{\partial \widetilde{\mathrm{n}}}=\frac{\mathrm{a}^{2}}{2} \widetilde{\mathrm{T}}
$$

The parameter (a) that emerged in eq. (9) is the same that Bejan and Almogbel defined in Ref (Bejan and Almogbe, 2000) as:

$$
\mathrm{a}=\left(\frac{2 \mathrm{hA}}{\mathrm{k}}\right)^{1 / 2}
$$

The numerical method and simulation procedure are the same used in Section 2. Figure 7 demonstrates that there is an optimal shape for the elliptical cavity for all the studied volume fractions. The minimal global thermal resistance decreases when the volume fraction increases and the optimal results are shown in Fig. 8. Figure 8 also indicates that the optimal shape of the elliptical cavity calculated in this section is very similar to the optimal shapes shown in Fig. 3. Our conclusion is that the optimal shape of the elliptical cavity is independent of the thermal boundary conditions.

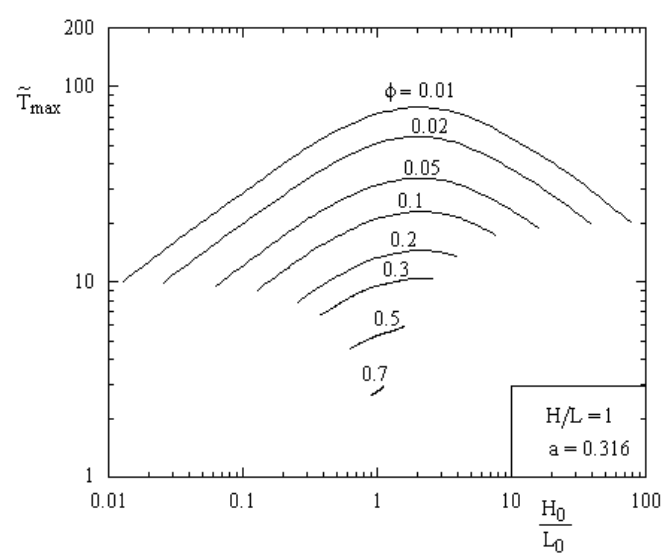

Figure 7. The minimization of the global thermal resistance when the external shape of the heat generating body is fixed. 


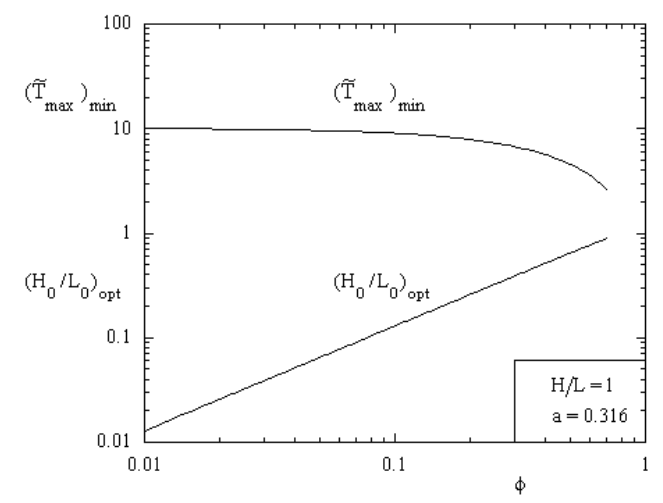

Figure 8 . The optimized geometry and performance when the external shape is square (a fixed).

Figure 9 illustrates how the global thermal resistance decreases when the parameter (a) increases. This figure also shows that the optimal shape of the elliptical cavity does not depend on the parameter (a).

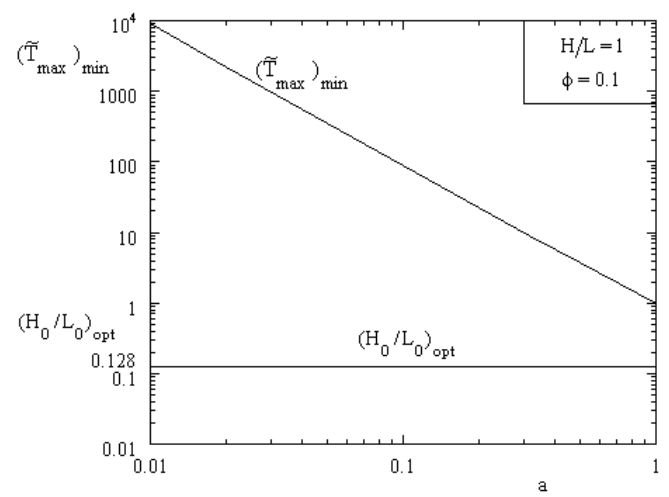

Figure 9. The optimized geometry and performance when the external shape is square ( $\phi$ fixed).

\section{CONCLUSIONS}

Several conclusions and ideas for future research emerged from this study. We considered the original engineering focus of the constructal method, i.e. the optimization of architecture referred to a basic configuration: an isothermal elliptical cavity intruding into a rectangular conducting body. In the second step of the numerical investigation, a "double minimization" of the thermal resistance, i.e., the optimization of geometry with respect to all degrees of freedom has been contemplated. Based on pure observation, we found that the optimized cavity is the one that penetrates the solid almost completely and that the thermal resistance decreases when the volume fraction $(\phi)$ occupied by the cavity increases. It is also interesting to observe that there is an unique best shape of the internal cavity for all external shape $(\mathrm{H} / \mathrm{L})$ values, except for $\mathrm{H} / \mathrm{L}=2$. When $\mathrm{H} / \mathrm{L}$ is equal to 2 can exist two possibilities for the optimal internal shape of the elliptical cavity $\left(H_{0} / L_{0}\right)_{o p t}$ depending on the value of the volume fraction.

In the final part of the paper we optimized the elliptical cavity when it is cooled by heat transfer convection. The main remark is that the optimal shape of the elliptical cavity is practically insensitive to the thermal boundary conditions. We also discovered that the optimal shape of the elliptical cavity does not depend on the dimensionless parameter (a).

\section{ACKNOWLEDGEMENTS}

Prof. Luiz Rocha's work was sponsored by FAPERGS, Porto Alegre, RS, Brazil. Prof. Enrico Lorenzini and Prof. Cesare Biserni were funded by Italian MIUR.

\section{REFERENCES}

Bejan, A., 2000, Shape and Structure, from Engineering to Nature, Cambridge University Press, Cambridge, UK.

Bejan, A., 1997, Advanced Engineering Thermodynamics, second ed., Wiley, New York, Chapter 13.

Lorenzini, G., and Rocha, L. A., 2006, Constructal design of Y-shaped assembly of fins, International Journal of Heat and Mass Transfer, Vol. 49, pp. 4552-4557.

Lorenzini, G., and Moretti, S., 2007, Numerical analysis of heat removal enhancement with extended surfaces, International Journal of Heat and Mass Transfer, Vol. 50, pp. 746-755.

Lorenzini, G., and Moretti, S., 2007, Numerical analysis on heat removal from Y-shaped fins: Efficiency and volume occupied for a new approach to performance optimization, Int. J. Thermal Sciences, Vol. 46, pp. 573-579.

Bejan, A., 1998, Constructal theory: from thermodynamic and geometric optimization to predicting shape in nature, Energy Convers. Manage, Vol. 39, pp. 1705-1718.

Bejan, A., and Badescu, V., 2000, Constructal theory of economics, Appl. Energy, Vol. 67, pp. 3760.

Bejan, A., Badescu, V., and De Vos, A., 2000, Constructal theory of economics structure generation in space and time, Energy Convers. Manage, Vol. 41, pp. 1429-1451.

Wang. H, Dai, W., and Bejan, A., 2007, Optimal temperature distribution in a 3D triple-layered skin structure embedded with artery and vein vasculature and induced by electromagnetic radiation, Int. J. Heat Mass Transfer, Vol. 50, pp. 1843-1854.

Arion, V., Cojocari, A., and Bejan, A., 2003, Integral measures of electric power distribution networks: load-length curves and line-network multipliers, Energy Convers. Manage, Vol.44, pp. 1039-1051. 
Bejan, A., 1997, Constructal-theory network of conducting paths for cooling heat generating volume, Int. J. Heat Mass Transfer, Vol. 40, pp. 799-816.

MATLAB, User's Guide, version 6.0.088, release 12, 2000, The Mathworks Inc.

Biserni, C., Rocha, L. A. O., and Bejan, A., 2004, Inverted fins: geometric optimization of the intrusion into a conducting wall, International Journal of Heat and Mass Transfer, Vol. 47, pp 2577-2586.

Rocha L. A. O., Lorenzini, E., and Biserni, C., 2005, Geometric optimization of shapes on the basis of Bejan's Constructal Theory. International Communications in Heat and Mass Transfer, Vol. 32, pp. 1281-1288.

Bejan, A., and Almogbel, M., 2000, Constructal T-shaped fins, Int. J. Heat Mass Transfer, Vol. 43, pp.2101-2115. 